\title{
Thermophilic co-digestion of food waste and sewage sludge
}

\author{
Jamie Ka Yan Li \\ Department of Civil Engineering, The University of Hong Kong, Hong Kong, People's Republic of China
}

\begin{abstract}
Due to the rising concerns regarding food waste disposal as well as the increasing demand for renewable energy nowadays, a number of European countries have adopted anaerobic co-digestion, a technology that deals with food waste and sewage sludge. As stated in the HKSAR Government's Policy Address 2016, the feasibility of using existing sewage treatment facilities for co-digestion of food waste and sewage sludge has been under exploration. A trial scheme has been commenced in 2019. This paper aims to compare the efficiency of biogas production and volatile solid reduction in codigestion of food waste and sewage with mono-digestion in laboratory scale.
\end{abstract}

KEYWORDS Thermophilic; co-digestion; anaerobic digestion; food waste; sewage sludge; biogas CONTACT Jamie Ka Yan Li@jamieliky@gmail.com

Received 15 March 2019

\section{Introduction}

\subsection{Background}

Sewage sludge is a major, yet inevitable by-product of the wastewater treatment process (Show et al., 2012). Since sewage sludge is a mixture of primary and biological sludge (Iacovidou et al., 2012), which primarily consists of a rich amount of pathogens, heavy metals and environmental pollutants (Show et al., 2012a), anaerobic digestion has been adopted widely for the digestion of sewage sludge, during which stabilisation and volatile solid reduction can be achieved before final disposal. In anaerobic digestion, organic matters are digested, and as a consequence, biogas and digestates are produced. Biogas, such as methane, is a good renewable source for energy generation.

In recent years, many studies have investigated the possibility of adding other substrates such as grease waste (Silvestre et al., 2011), shredded grass (Hidaka et al., 2013) and landfill leachate (Montusiewicz and Lebiocka, 2011) into sewage sludge. The process of adding other substrates to the digestion of sewage sludge is termed co-digestion, which allows the two substrates to provide supplementary effect to the process; for instance, improving the generation of biogas by increasing the efficiency of digestion, when compared to mono-digestion. Various studies have focused on the governing factors of co-digestion. With the high organic contents in food waste, studies have found that the combination of food waste and sewage sludge can help optimise the performance of anaerobic digestion. In this project, the co-digestion of food waste and sewage sludge will be examined under controlled and stable environment with pre-determined mixing ratio of food waste and sewage sludge in reactors, with the aim to study the performance of co-digestion in the local context in Hong Kong.

\subsection{Motivation}

The demand for renewable energy generation has increased in recent years; as a result, there is a pressing need to divert municipal waste from landfill. The total solid waste, under the framework of solid waste statistics, comprises municipal solid waste, overall construction waste and special waste (Census and Statistics Department, 2018). Among solid waste, food waste accounts for 3,337 tonnes, over one-third of municipal solid waste in Hong Kong. The disposal of food waste to landfill is not sustainable due to the limited space, and causes a series of environmental problems due to the landfill gas and odour generated (Environmental Protection Department, 2018). Despite the fact that a number of alternatives, such as incineration, use of food waste disposal units and composting, have been proposed for the management of food waste, food waste is difficult to handle because of its high water content and high degradability (Iacovidou et al., 2012). Conversely, the suggestion of adopting anaerobic digestion for food waste management has attracted more interest of policy makers due to the possibility of the generation of energy in the process (Iacovidou et al., 2012). On the other hand, sewage sludge is classified as one of the major special waste, under the classification of solid wastes, produced from wastewater treatment plants. From the 11 sewage treatment works in Hong Kong, over 1,200 tonnes of sludge are generated every day (T-PARK, 2018). In 2017, the total amount of sewage sludge collected by sludge treatment facility reached over 380,000 tonnes (Census and Statistics Department, 2018). The HKSAR Government is keen in maximising the utilisation of sludge, as well as minimising their volume before final disposal. In 2015, a treatment facility for dewatered sewage sludge, namely T-PARK, was commissioned. However, with the growing population and development of the city, sludge production will rise further in the near future. 


\subsection{Approach and scope}

This is an experimental study. The majority of the works were conducted in laboratory with different experimental stages, from batch experiment to semicontinuous experiment. The performance of co-digestion under thermophilic condition at laboratory scale was evaluated based on the analysis of results obtained from experiments.

\subsection{Objectives}

In view of the problems arisen from food waste disposal and the production of sewage sludge, this study aims to examine the performance of co-digestion of food waste and sewage sludge under thermophilic conditions. Reactors with different food waste (FW) to feeding sewage sludge (FSS) ratio will be set up to compare the performance of mono-digestion and co-digestion of food waste and sewage sludge, whereby parameters will be tested to evaluate the performance of each of the set-up conditions. The following objectives will be accomplished upon the completion of this study: 1) to evaluate the performance of biogas production of co-digestion and mono-digestion under thermophilic condition; 2) to determine the yield of methane and the percentage of volatile solid reduction; and 3) to determine the effect of inhibitors of co-digestion.

\section{Literature review}

\subsection{Anaerobic digestion of sewage sludge}

The process of digestion of sewage sludge is anaerobic, during which oxygen is absent while organic matters are being digested, and biogas and digestates are produced. The four major stages in anaerobic digestion that lead to methane generation are hydrolysis, acidogenesis, acetogenesis and methanogensis. The process is illustrated in Figure 1.

In hydrolysis, complex compounds such as carbohydrates, proteins and lipids are broken down into simpler, soluble organic acids, sugars and amino acid, during which some acetic acid, hydrogen and carbon dioxide are produced (Parkin and Owen, 1986). The process is followed by acidogenesis, where organic acids are further broken down into smaller organic acids such as propionic acid and butyric acid (Parkin and Owen, 1986). Subsequently, acetogenic bacteria is involved in the production of acetic acid, while hydrogen and carbon dioxide are also formed. At the same time, some acetic acid is also produced by hydrogen-consuming acetogenic bacteria from hydrogen (Parkin and Owen, 1986). At the final stage, over $70 \%$ of the methane are generated from acetic acid by aceticlastic methanogens during methanogenesis, while the rest of the methane is converted from hydrogen and carbon dioxide by $\mathrm{CO}_{2}$-reducing methanogens.

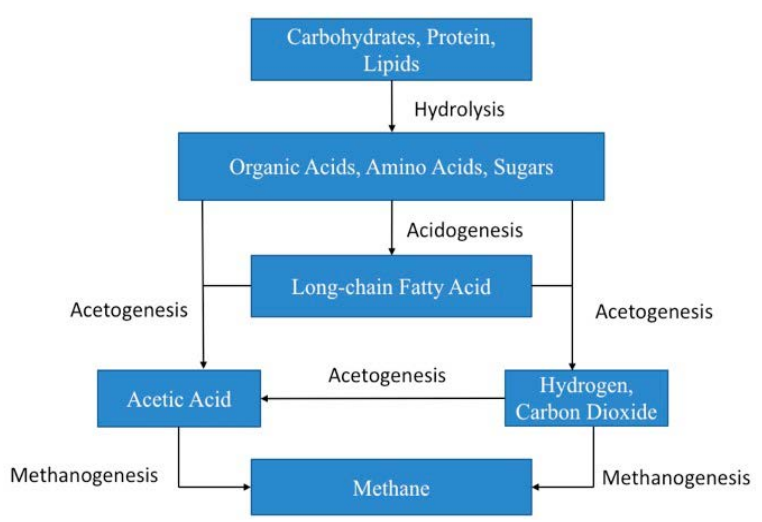

Figure 1. Mechanism of the production of methane (Parkin and Owen, 1986).

\subsection{Significant factors}

There are a number of monitoring factors for the experiment to ensure the conditions are favourable for digestion to take place. Factors including temperature, $\mathrm{pH}$, carbon-to-nitrogen ratio and presence of inhibitors will be examined.

\subsubsection{Temperature}

Temperature is one of the major factors in determining the performance of anaerobic digestion because heat provides kinematic energy for micro-organisms to undertake the reaction in breaking down organic matters. There are generally temperature settings for anaerobic digestion: mesophilic condition at $35^{\circ} \mathrm{C}$ and thermophilic condition at $55^{\circ} \mathrm{C}$. Experiments in this study are to be carried out under thermophilic condition. Studies found that at higher temperature, more energy are provided for microorganisms, and subsequently, digestion process is facilitated with higher reaction rate, resulting in a higher volatile solid reduction and an increased production of biogas (Gou et al., 2014).

\subsection{2. $\mathrm{pH}$}

The optimum $\mathrm{pH}$ range for anaerobic digestion is 6.8 - 7.5. During anaerobic digestion as shown in Figure 1, organic acids are generated. The addition of FW is likely to further lower the $\mathrm{pH}$ in reactors due to the accumulation of volatile fatty acids (VFAs). If $\mathrm{pH}$ falls below the optimum range, the digestion will be inhibited and VFAs will be the final product of the digestion. Therefore, the $\mathrm{pH}$ of each reactor has to be monitored on the next day of feeding, and sodium bicarbonate in a concentration of $5 \mathrm{~g} / 100 \mathrm{~mL}$ has to be added to increase the $\mathrm{pH}$. 


\subsubsection{Carbon-to-nitrogen ratio}

Carbon-to-nitrogen ratio $(\mathrm{C}: \mathrm{N})$ is also one the factors that affect the process of anaerobic digestion as well as an indicator of how degradable a substrate is. The best condition is to adopt the optimum C: $\mathrm{N}$ of 20 - 30 (Iacovidou et al., 2012). If $\mathrm{C}: \mathrm{N}$ is above 30 , there is a deficiency of nitrogen such that insufficient nutrient is provided for the digestion and will cause instability; in contrast, if $\mathrm{C}: \mathrm{N}$ is below 6 , it is an indication of low carbon availability with a large amount of ammonia generation, which can lead to toxicity to micro-organisms (Iacovidou et al., 2012).

\subsubsection{Inhibitors}

The presence of inhibitors poses a major challenge in the co-digestion process of food waste and sewage sludge because they adversely affect the digestion process. Ammonium nitrogen, volatile fatty acid and metal ions are the main inhibitors that inhibit the reaction process.

\subsection{Characteristics of FW}

FW consists of a variety of food disposed from different areas in a city and therefore has a large variation in its composition. This may as well be due to seasonal changes in food consumption patterns, habits and dining culture. FW is charaterised by large compositions of carbohydrates, lipids and proteins, making it highly degradable with high $\mathrm{C}: \mathrm{N}$ due to the high proportion of carbon it contains. The proportion of each of the organic components differs considerably in different kinds of food. For example, vegetables are rich in carbohydrates, while nuts are rich in protein and lipids. Apart from its high organic contents, FW also has high water content and is rich in volatile solid (VS), which makes it easier to convert substrates into methane in the digestion process (Prabhu and Mutnuri, 2016). However, there are concerns regarding the lipid contents of FW, which may cause the accumulation of VFAs, leading to acidification of substrate. If the substrate is acidic and below the desirable range of $\mathrm{pH}$ values, the digestion process will be inhibited. Moreover, since FW has a relatively low content of nitrogen and phosphorus, digestion will be inhibited due to insufficient nutrients. With a suitable amount of sodium ion, $\mathrm{Na}^{+}$, the inhibition caused by ammonia can be avoided. However, the high salt content of $\mathrm{FW}$ with a high concentration of $\mathrm{Na}^{+}$is one of the inhibiting factors of the mono-digestion of FW (Dai et al., 2012).

Based on the food consumption pattern in Hong Kong, FW generally consists of $80 \%$ carbohydrates, $15 \%$ proteins and 5\% lipids (Wang et al., 2015). Therefore, this distribution of organic matters in FW is adopted in this study and the FW is prepared accordingly for the experiment.

\subsection{Characteristics of sewage sludge}

When compared with FW, sewage sludge has lower $\mathrm{C}: \mathrm{N}$, ranging from 6 - 9 (Iacovidou et al., 2012) due to its lack of organic matters. The generation of ammonia, which poses a risk of inhibiting the digestion, is a major concern due to the low C:N. Sewage sludge also has a lower VS than FW, indicating it is less easily degradable than FW. Due to these factors, the digestion of sewage is comparatively less efficient than that of FW.

\subsection{Benefits of co-digestion}

With the constraints of mono-digestion of FW and sewage sludge discussed in Sections 2.3 and 2.4, it can be observed that the two substrates can overcome their limitations by adopting co-digestion, and thus the overall performance of digestion can be enhanced.

In the co-digestion of sewage sludge and FW, sewage sludge with low $\mathrm{C}: \mathrm{N}$ provides nitrogen for the nutrientdeficient FW, while FW with high $\mathrm{C}: \mathrm{N}$ improves the carbon content of sewage sludge. Therefore, a more balanced C:N can be achieved for an ideal digestion condition. Studies have also found that with the lower ratio of sewage sludge to FW, methane yield would be higher and volatile solid reduction (VSR) would also be increased (Dai et al., 2012). This phenomenon can be explained by the fact that FW is highly degradable, while sewage sludge is refractory to hydrolysis (Dai et al., 2012). In addition, the presence of FW in co-digestion improves the stability of the high ammonia digestion system, as well as dilutes toxicants in sewage sludge, and hence, increases the production of biogas (Dai et al., 2012). On the other hand, the addition of sewage sludge to FW helps dilute the high concentration of $\mathrm{Na}^{+}$in FW.

\subsection{Difficulties of co-digestion}

The major constraint in co-digestion is caused by $\mathrm{FW}$, due to its high variability in nature. Micro-organisms in a digestion system are sensitive to the organic contents in FW and the performance of digestion depends on the composition of FW, which are carbohydrates, proteins and lipids. If the organic composition of FW changes, the system becomes unstable because micro-organisms have adapted to specific substrates and the reaction process will be affected (Iacovidou et al., 2012). Therefore, it is crucial to maintain the composition of FW added to the system.

\section{Methodology}

\subsection{Overview}

The experiment is divided into two main stages: batch experiment and semi-continuous experiment. The 
activity and adaptation of methanogens under $55^{\circ} \mathrm{C}$ is monitored regularly in the first stage, while regular feeding is undertaken in the second stage to perform co-digestion and mono-digestion in reactors.

In order to investigate the performance of co-digestion, three sets of reactors are set up at FW to FSS ratio of 0:100, 50:50 and 100:0. Each set-up is duplicated, and therefore, six reactors are used in total. Although the volume of each reactor is over $500 \mathrm{~mL}$, the actual working volume is set as $200 \mathrm{~mL}$. The two substrates used in co-digestion are FSS and FW. FSS is a mixture of thickened primary sludge (TPS) and thickened secondary activated sludge (TSAS) collected from Tai Po Sewage Treatment Works (TPSTW). FSS was prepared by mixing TPS and TSAS at a ratio of $4.5: 1$ before the experiment. Solid retention time (SRT) of 20 days is adopted in this experiment. With the working volume of $200 \mathrm{~mL}$ and the feeding of substrates every four days, a total volume of $40 \mathrm{~mL}$ of digestate has to be discharged before each feeding.

\subsection{Pre-experimental set-up}

Digested sludge (DS) collected from TPSTW is used as inoculum, which is the micro-organism used for digestion, in the experiment. Since the sludge was stored at mesophilic condition at $35^{\circ} \mathrm{C}$ for digestion at Sewage Treatment Works, adaptation and activation of microorganisms was required at thermophilic condition, i.e. $55^{\circ} \mathrm{C}$ before the commencement of the experiment. This was done by mixing DS and FSS at a ratio of 2:1, where $134 \mathrm{~mL}$ of DS and $66 \mathrm{~mL}$ of FSS are added to each reactor. The prepared inoculum was then kept in a water bath at a temperature of $55^{\circ} \mathrm{C}$ for two weeks. The activities and adaptation of inoculums were monitored by the measurement of biogas production as well as the methane yield.

\subsection{Experimental set-up}

Upon the completion of batch stage, reactors can be set up for the next stage. In the experiment, three types of reactors with different ratios of FW:FSS are set up. The set-up ratio of FW:FSS in reactor R1 and R2, R3 and R4, and R5 and R6 are 0:100, 50:50 and 100:0, respectively. FW and FSS are classified as feeding, while the digestate in the reactors from batch stage are used as inoculum. To prepare for the next stage, all digestate in each reactor after batch stage were mixed together before using as inoculum to ensure the unity of the performance of inoculum in each reactor. The ratio of inoculum to feeding in the working volume of $200 \mathrm{~mL}$ is $2: 1$.

FW with $80 \%$ carbohydrates, $15 \%$ proteins and $5 \%$ lipids was prepared with bread, steamed rice, cooked meat, lettuce and apples. The amount of FW added into each reactor depends on the total solid (TS) of FSS.

Since salt was present in FSS and the calculated TS of FSS with salt will affect accuracy of the TS required from
FW, the salt in FSS has to be removed before measuring the TS of FSS. The TS of desalted FSS was then obtained. Compared with the TS of un-desalted FSS of $23.56 \mathrm{~g} / \mathrm{L}$, the TS of desalted FSS was $13.5 \mathrm{~g} / \mathrm{L}$, which is unusually lower than expected. This may be due to the daily variation of water consumption, resulting in the variation in the amount of TS in sewage collected from TPSTW. To solve the problem, the above procedures were repeated using thickened FSS. The TS of the thickened and desalted FSS is $38.59 \mathrm{~g} / \mathrm{L}$, and the TS of FW was $23.85 \%$. The total volume of the initial feeding is $66 \mathrm{~mL}$ and the amount of FW and FSS added for each reactor is summarised in Table 1.

Table 1. Amount of FW and FSS, and corresponding TS added to each reactor in batch stage.

\begin{tabular}{|c|c|c|c|c|c|}
\hline Reactor & FW:FSS & $\begin{array}{c}\text { Weight of } \\
\text { FW added } \\
\mathbf{( g )}\end{array}$ & $\begin{array}{c}\text { TS added } \\
\text { from FW } \\
\mathbf{( g )}\end{array}$ & $\begin{array}{c}\text { Volume of } \\
\text { FSS added } \\
\text { (mL) }\end{array}$ & $\begin{array}{c}\text { TS added } \\
\text { from FSS } \\
\text { (g) }\end{array}$ \\
\hline R1, R2 & $0: 100$ & 0 & 0 & 33 & 2.547 \\
\hline R3, R4 & $50: 50$ & 5.34 & 1.273 & 33 & 1.273 \\
\hline R5, R6 & $100: 50$ & 10.68 & 2.547 & 0 & 0 \\
\hline
\end{tabular}

\subsection{Operation of experiment}

Semi-continuous feeding of FW and FSS into reactors is the main part of the experiment. $40 \mathrm{~mL}$ of feeding were added to the reactors. The total weight of FW and volume of FSS added to reactors in each feeding is summarised in Table 2. Water was added to FW so that the total volume of FW mixture fed into reactors was $20 \mathrm{~mL}$ for R3 and R4, and $40 \mathrm{~mL}$ for R5 and R6. After each feeding, oxygen was removed by purging nitrogen into reactors for one minute. Reactors were sealed with rubber septa and aluminium cap at the end of the process. The $\mathrm{pH}$ values of each reactor were also monitored to ensure an optimum $\mathrm{pH}$ range from 6.8 to 7.5 . If $\mathrm{pH}$ drops below the optimum values, sodium bicarbonate was added for adjustment.

Table 2. Amount of FW and FSS, and corresponding TS added to each reactor in each feeding.

\begin{tabular}{|c|c|c|c|c|c|}
\hline Reactor & FW:FSS & $\begin{array}{c}\text { Weight of } \\
\text { FW added } \\
\text { (g) }\end{array}$ & $\begin{array}{c}\text { TS added } \\
\text { from FW } \\
\text { (g) }\end{array}$ & $\begin{array}{c}\text { Volume of } \\
\text { FSS added } \\
\text { (mL) }\end{array}$ & $\begin{array}{c}\text { TS added } \\
\text { from FSS } \\
\text { (g) }\end{array}$ \\
\hline R1, R2 & $0: 100$ & 0 & 0 & 40 & 1.543 \\
\hline R3, R4 & $50: 50$ & 3.24 & 0.771 & 20 & 0.771 \\
\hline R5, R6 & $100: 50$ & 6.47 & 1.543 & 0 & 0 \\
\hline
\end{tabular}

\section{Measurements and results}

\section{1. $V S R$}

The efficiency in the reduction of VS is one of the important parameters in monitoring the performance of digestion in a reactor. VSR was obtained by comparing the difference between VS in each feed and the VS in effluent. The higher reduction in VSR is, the more organic matters 
are removed during the digestion process. In general, the reduction of VS is the lowest in mono-digestion of FSS, with an average of $37.4 \%$, while the reduction of VS is the highest in mono-digestion of FW, with an average of $80.4 \%$. The average efficiency of VSR of co-digestion is $52.4 \%$, in which the reduction efficiency is between monodigestion of FSS and mono-digestion of FW. These results show that with the presence of FW in substrate, higher efficiency of VSR can be achieved because more organic matters are present in FW, making FW highly degradable. Therefore, mono-digestion of FW has the highest reduction in VS, while the co-digestion of FW and FSS has a higher VSR than mono-digestion of FSS.

\subsection{Biogas and methane production rate}

The volume of biogas produced in a cycle was measured on the day of feeding and the day after feeding. In Figure 2, biogas production rate was the highest for mono-digestion of FW at the first half of the experiment among all reactors, ranging from $595 \mathrm{~mL} / \mathrm{L} / \mathrm{D}$ to $1000 \mathrm{~mL} /$ L/D. However, gas production rate dropped significantly in the latter half of the experiment due to the presence of inhibitors, such as accumulation of VFAs. The gas production rate of co-digestion was the most steady, fluctuating between $580 \mathrm{~mL} / \mathrm{L} / \mathrm{D}$ and $680 \mathrm{~mL} / \mathrm{L} / \mathrm{D}$, while that of mono-digestion of FSS attained the lowest value throughout the experiment, ranging between $250 \mathrm{~mL} /$ $\mathrm{L} / \mathrm{D}$ and $480 \mathrm{~mL} / \mathrm{L} / \mathrm{D}$. With the measurement on gas composition after the measurement on gas volume, the proportion of methane in biogas is approximately $40 \%$ $50 \%$. Therefore, a similar pattern was observed for methane production rate as in biogas production rate in Figure 2.

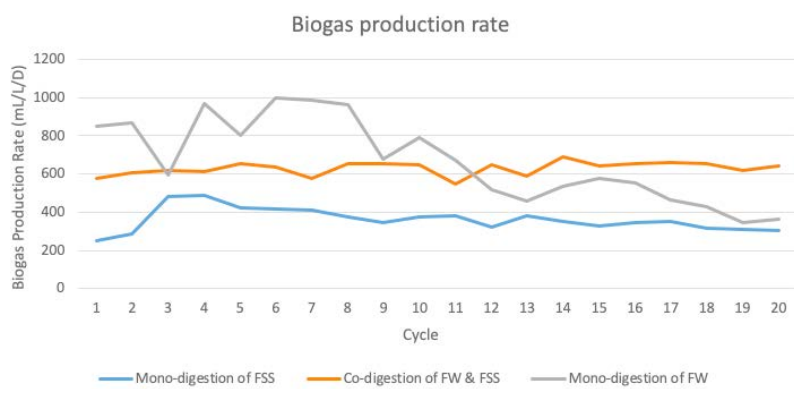

Figure 2. Gas production rate.

\subsection{Biogas and methane yield}

Biogas yield is defined as the volume of biogas produced per gram of VSR. This is an indication of the amount of energy recovery in the digestion process. Biogas yield is the most stable for co-digestion, ranging between $485 \mathrm{~mL} / \mathrm{g}$ VSR and $749 \mathrm{~mL} / \mathrm{g} \mathrm{VSR}$, while mono-digestion of FSS attained the highest yield at the first seven cycles from $485 \mathrm{~mL} / \mathrm{g}$ VSR to $1083 \mathrm{~mL} / \mathrm{g}$ VSR. The biogas yield for mono-digestion of FW fluctuated between $250 \mathrm{~mL} / \mathrm{g}$ VSR and $710 \mathrm{~mL} / \mathrm{g}$ VSR and attained the lowest value at the end of the experiment.

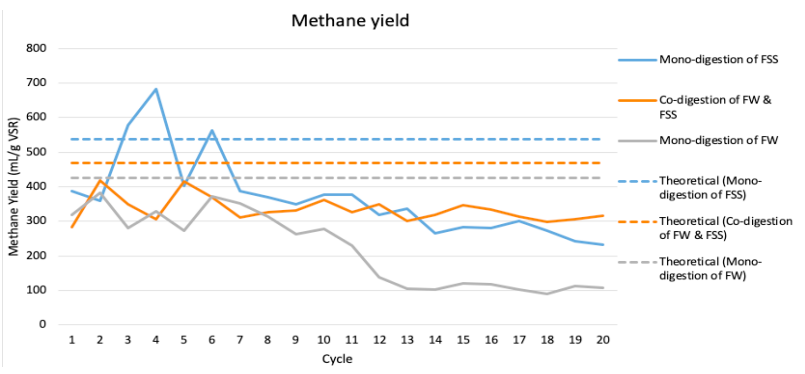

Figure 3. Methane yield.

Figure 3 shows the theoretical and experimental methane yield of digestion. Performance gaps can be seen between the theoretical yield and the experimental yield because inhibitors are present in reactors, such as ammonium nitrogen in mono-digestion of FSS and VFAs in mono-digestion of FW. The performance gap is the smallest in co-digestion.

\subsection{Concentration of total organic carbon (TOC)}

The measurement of the concentration of TOC is the concentration of organic carbon in the effluent from reactors in each feeding cycle. The accumulation of VFAs contributes to the concentration of TOC. The concentration of TOC in reactors with mono-digestion of FSS and codigestion of FW and FSS were approximately the same and remained steady, ranging between $300 \mathrm{mg} / \mathrm{L}$ and $880 \mathrm{mg} / \mathrm{L}$, while that for the mono-digestion of FW remained steady at the first eight cycles at similar range as in other reactors, followed by a sharp increase in the concentration up to $4090 \mathrm{mg} / \mathrm{L}$ at the end of the experiment. This can explain the inhibition effect in R5 and R6, which has led to a sharp drop in methane production in the reactors at the later stage of the experiment.

\subsection{Concentration of VFAs}

VFAs are one of the most critical inhibitors in anaerobic digestion. In case of high accumulation of VFAs, $\mathrm{pH}$ value drops out of the optimum range, leading to an inhibition effect on digestion. The concentration of VFAs in mono-digestion of FSS and mono-digestion of FW and FSS remains relatively low at a concentration of $175 \mathrm{mg} / \mathrm{L}$ $350 \mathrm{mg} / \mathrm{L}$, with heptanoic acid being dominant. On the other hand, the concentration of VFAs in mono-digestion of FW had a rapid increase from cycle nine onwards, reaching a concentration of over 20 times higher than all other reactors, with acetic acid being dominant, causing a serious inhibiting effect on digestion. 
Table 3. Mass balance.

\begin{tabular}{|c|c|c|c|c|c|c|}
\hline \multirow{2}{*}{ Reactor } & \multirow{2}{*}{ Input COD (g) } & \multicolumn{3}{|c|}{ Output COD (g) } & \multirow{2}{*}{$\begin{array}{c}\text { Total output } \\
\text { COD (g) }\end{array}$} & \multirow{2}{*}{$\begin{array}{c}\text { Coverage rate } \\
(\%)\end{array}$} \\
\hline & & $\mathrm{COD}_{\text {gas }}(\mathrm{g})$ & $\mathrm{COD}_{\text {liquid }}(\mathrm{g})$ & $\mathrm{COD}_{\text {solid }}(\mathrm{g})$ & & \\
\hline R1 & \multirow{2}{*}{1.81} & 0.535 & 0.0796 & 0.984 & 1.598 & 88 \\
\hline $\mathbf{R 2}$ & & 0.514 & 0.0576 & 1.037 & 1.608 & 89 \\
\hline R3 & \multirow{2}{*}{1.77} & 0.816 & 0.0605 & 0.606 & 1.483 & 84 \\
\hline R4 & & 0.825 & 0.0582 & 0.611 & 1.494 & 84 \\
\hline $\mathbf{R 5}$ & \multirow{2}{*}{1.66} & 0.723 & 0.236 & 0.417 & 1.375 & 83 \\
\hline R6 & & 0.741 & 0.218 & 0.371 & 1.330 & 80 \\
\hline
\end{tabular}

\subsection{Concentration of ammonium nitrogen $\left(\mathrm{NH}_{4}^{+}-\mathrm{N}\right)$}

$\mathrm{NH}_{4}{ }^{+}-\mathrm{N}$ is an inhibitor that presents at a high concentration in FSS. The concentration of $\mathrm{NH}_{4}{ }^{+} \mathrm{N}$ is the highest for the mono-digestion of FSS, ranging between 800 $\mathrm{mg} / \mathrm{L}$ and $1025 \mathrm{mg} / \mathrm{L}$, while its concentration is the lowest in reactors undergoing mono-digestion of $\mathrm{FW}$, ranging from $213 \mathrm{mg} / \mathrm{L}$ to $654 \mathrm{mg} / \mathrm{L}$. The concentration of $\mathrm{NH}_{4}^{+}-\mathrm{N}$ in reactors undergoing co-digestion ranges between the concentrations of the other two types of reactors. Overall, there was a decreasing trend in the concentration of $\mathrm{NH}_{4}^{+}-\mathrm{N}$ as the experiment proceeded. The high concentration of $\mathrm{NH}_{4}{ }^{+} \mathrm{N}$ in mono-digestion of FSS can explain the phenomenon that reactors undergoing this kind of reaction always have the lowest gas production rate, when compared with co-digestion of FW and FSS and mono-digestion of FW. It is also found that the concentration of $\mathrm{NH}_{4}{ }^{+} \mathrm{N}$ can be lowered by the addition of $\mathrm{FW}$ into digestion, achieving co-digestion.

\subsection{Mass balance}

In checking the validity of the results, a mass balance on chemical oxygen demand (COD) was calculated and summarised in Table 3. In R1 and R2, the reactors undergoing mono-digestion of FSS, mass balance coverage of $88 \%-89 \%$ was achieved. This is within the range of acceptable percentage of coverage of $100 \% \pm 20 \%$. However, for R3 and R4, the reactors undergoing codigestion of FW and FSS, and R5 and R6, the reactors undergoing mono-digestion of $\mathrm{FW}$, have seen a lower coverage rate in mass balance calculation of $80 \%-84 \%$. This is likely due to the fact that biogas produced is leaked from the reactors during measurement with the limited headspace of $300 \mathrm{~mL}$, while the volume of gas produce could go beyond $400 \mathrm{~mL}$.

\section{Limitations}

The major limitation of the experiment is the limited headspace volume in reactors, and the addition of sodium bicarbonate solution in adjusting the $\mathrm{pH}$ in $\mathrm{R} 5$ and $\mathrm{R} 6$ further reduced the headspace volume to accommodate the biogas produced. Therefore, it is suggested that experiment in a larger scale with larger reactors should be conducted in future when investigating co-digestion.

\section{Conclusion}

With the goal to improve the efficiency of biogas production from anaerobic digestion and to alleviate the problems arisen from the disposal of food waste, a trial scheme on co-digestion of food waste and sewage sludge has been commissioned in 2019. This study has investigated the performance of co-digestion under thermophilic condition. To conclude, co-digestion of FW and FSS can achieve more steady and efficient production of biogas such as methane, while the percentage of VSR was higher when compared to mono-digestion of FSS. The overall stability of the digestion system can be improved in co-digestion. However, it is recommended that future experiment should be carried out in a larger scale, as well as using different FW to FSS scale in digestion to gain a further investigation on co-digestion in treatment plants.

\section{Notes on Contributor}

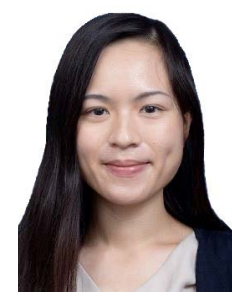

Miss Jamie Ka Yan Li received her B.Eng. degree in Civil Engineering in The University of Hong Kong. She has undertaken a range of studies and experiments on the topic of thermophilic co-digestion of food waste and sewage sludge for her final year project. She is now a Graduate Engineer in MTR Corporation Limited. 


\section{References}

[1] Census and Statistics Department (2018). Statistics on sludge disposal and treatment in Hong Kong. Hong Kong Monthly Digest of Statistics. pp. FB1-FB3. [online]. Available at: <https://www.statistics.gov.hk/ pub/B71802FB2018XXXXB0100.pdf>. [Accessed on 19 September 2018].

[2] Dai X, Duan N, Dong B and Dai L (2012). Highsolids anaerobic co-digestion of sewage sludge and food waste in comparison with mono digestions: Stability and performance. Waste Management, 33, pp. 308-316.

[3] Environmental Protection Department (2018). Food waste challenge. [online]. Environmental Protection Department. Available at: < https://www.epd.gov.hk/ epd/english/environmentinhk/waste/prob_solutions/ food_waste_challenge.html $>$. [Accessed on 19 September 2018].

[4] Gou C, Yang Z, Huang J, Wang H, Xu H and Wang L (2014). Effects of temperature and organic loading rate on the performance and microbial community of anaerobic co-digestion of waste activated sludge and food waste. Chemosphere, 105, pp. 146-151.

[5] Hidaka T, Arai S, Okamoto S and Uchida T (2013). Anaerobic co-digestion of sewage sludge with shredded grass from public green spaces. Bioresource Technology, 130, pp. 667-672.

[6] HKSAR Government (2016). 2016 Policy Address. [online]. Available at: $<$ https://www.policyaddress. gov.hk/2016/eng/p208.html>. [Accessed on 20 September 2018].

[7] Iacovidou E, Ohandja G and Voulvoulis N (2012). Food waste co-digestion with sewage sludge - Realising its potential in the UK. Journal of Environmental Management, 112, pp. 267-274.

[8] Montusiewicz A and Lebiocka M (2011). Codigestion of intermediate landfill leachate and sewage sludge as a method of leachate utilization. Bioresource Technology, 102, pp. 2563-2571.

[9] Parkin G and Owen W (1986). Fundamentals of anaerobic digestion of wastewater sludges. Journal of Environmental Engineering, 112 (5), pp. 867-920.

[10] Prabhu M and Mutnuri S (2016). Anaerobic codigestion of sewage sludge and food waste. Waste Management \& Research, 34, pp. 307-315.

[11] Show K, Lee D and Tay J (2012). Anaerobic digestion of sewage sludge. Biological Sludge Minimization and Biomaterials/Bioenergy Recovery Technologies, pp. 319-347.

[12] Silvestre G, Reodriguez-Abalde A, Fernandez B, Flotats X and Bonmati A (2011). Biomass adaptation over anaerobic co-digestion of sewage sludge and trapped grease waste. Bioresource Technology, 102, pp. 6830-6836.
[13] T-PARK (2018). What is Sludge?. [online]. Available at: $<$ https://www.tpark.hk/en/story/>. [Accessed on 18 September 2018].

[14] Wang Y, Wang Y, Xia Y, Ju F and Zhang T (2015). Co-digestion of food waste with sewage sludge. In: Drainage Services Department Research \& Development Forum 2015. [online]. Hong Kong: Drainage Services Department. Available at : <https:// www.dsd.gov.hk/rdforum/2015/files/en/presentation/ D1T1.pdf $>$. [Accessed on 18 September 2018]. 